\title{
Mauro Bartolo
}

\section{Marina Cestari \\ Board of Director European Society of Lymphology; and Pianeta Linfedema Study Center, Terni, Italy}

\section{My mentor Professor Mauro Bartolo}

It was 1983 when, during the opening of the monographic work Prophylaxis and therapy of arteriosclerosis ${ }^{1}$ written by Professor Mauro Bartolo, head of the Angiology Division of the San Camillo Hospital of Rome, I was struck by his introduction, an old adage: It is in walls that doors are mounted, and by his final remark, when he mentioned the many griefs he experienced in life whenever I wanted to defend the interests of vascular patients, always suspected, and sometimes openly accused, of personal interest in promoting such a topic...

A man, a doctor to meet.

When we first met, he did not fail to convey his passion for Angiology to me and the sincere pleasure of meeting a young doctor who had decided to become an angiologist, without really knowing the meaning of that word, and an immediate feeling of rapport between us filled the room.

I instinctively understood that the charm of the Master went beyond his medical culture. In fact, while he was speaking with me quickly, he drew something behind a piece of cardboard he had casually found on his busy desk, a peculiar female face, that he then gave to me and which I still jealously preserve today. He was an artist who exhibited paintings in important art galleries and who was interested in interior architecture, but also a writer of novels and not only that, ${ }^{2-4}$ a man with a versatile mind - as Professor Antonio Strano defined him.

I began to attend the Department of Angiology daily, meanwhile increasingly crowded by students, a step behind the Master in sign of respect, but close enough to steal his medical art at the patient's bed with increasing admiration.

In the pocket of my coat I always had a Pocket-Doppler or, as the Master called it, the angiologist's phonendoscope, with which he studied chronic venous insufficiency through the bloodless measurement of venous pressures (in normal subjects, mean standing pressure levels are below 60 $\mathrm{mmHg}$. In varicose veins, average orthostatic pressures are 90-96 $\mathrm{mmHg}$ in deep and superficial veins, respectively. In the postphlebitic syndrome, mean values are about $100 \mathrm{mmHg}^{5}$ and more... just think of patients with arterial diseases.

The Master taught his immense knowledge to his students with communicative ease and without secrets, by ironically alternating medical phrases and phrases in Latin... and I was more and more fascinated. In the Roman school of angiology all the students, who also came from other Italian regions, learned clinical notions from the Master and, thanks to his team of highly qualified angiologists, the use of $\mathrm{CW}$ Doppler and then of Doppler ultrasonography.

Let us remember how angiology was made independent by Professor Mauro Bartolo with the wise, ironic style with which he used to deal with great medical issues.

Aware that angiology belonged to the culture of internal medicine, he believed it had the right to become a culturally autonomous subject. It was also due to his unceasing commitment and profound experience that angiology divisions and services first appeared in Rome, the elective seat of angiological knowledge, as the Roman school proved, and then on the rest of the national territory.

I would also like to recall how Professor Mauro Bartolo was a precursor to Italian lymphology, together with Professor Annarita Todini, a smart person with a vast scientific curiosity and moral rigor, when in the 80's they hospitalized lymphologic patients for diagnostic investigation and subsequent physiotherapy treatment. Lymphology was another lightning strike, after the one for my mentor. An interest that grew over the years and became a passion nourished by the scientific curiosity he had sown in me.

Professor Mauro Bartolo is no longer with us, but lives in every daily angiological gesture of us students who remember him for the enthusiasm, the rigor, the scientific curiosity, the ease and generosity of his scientific communication.

We also remember his motto Let us serve Angiology, not use Angiology.

I thank my mentor for illuminating me with his knowledge and helping me in difficult times, both during specialist training and in human growth.
Correspondence: Marina Cestari, Pianeta Linfedema Study Center, via Annio Floriano 3, 05100 Terni, Italy.

E-mail: cestari.marina@libero.it

Key words: Italian Phlebolymphology; history; Masters of the past; phlebology; lymphology.

Conflict of interests: the author declares no potential conflict of interests.

This paper is part of the monographic issue: ' $D i d$ the Masters of the past know the future? History and update of Italian Phlebolymphology' - Guest editor: Alberto Macciò (Phlebology - Part I edited by G. Agus; Phlebology - Part II edited by P. Bonadeo; Lymphology edited by F. Boccardo).

Received for publication: 30 June 2020.

Revision received: 10 July 2020.

Accepted for publication: 15 July 2020.

This work is licensed under a Creative Commons Attribution 4.0 License (by-nc 4.0).

OCopyright: the Author(s), 2020

Licensee PAGEPress, Italy

Veins and Lymphatics 2020; 9:9247

doi:10.4081/vl.2020.9247

\section{References}

1. Bartolo M. Profilassi e terapia dell'arteriosclerosi. Roma: Lombardo Editore; 1981.

2. Bartolo M. Prima che sia tardi. Roma: Edizioni Sipis;1994.

3. Bartolo M. Un figlio per cinque giorni. Roma: Edizioni Città Nuova; 1987.

4. Bartolo M. Una Cina due medicine. Roma: Edizioni Armando; 1983.

5. Bartolo M, Nicosia PM, Antignani PL, et al. Noninvasive venous pressure measurements in different venous diseases. A new case collection. Angiology 1983;34:717-23. 